\title{
Kasa Invaze Olmayan Mesane Kanserinde Transüretral Mesane Kanseri Rezeksiyonu (TUR-Tm): Nasıl Mükemmelliğe Ulaşılabilinir?
}

\author{
Transurethral Resection of Bladder Cancer (TUR-B) for Non-Muscle Invasive Bladder \\ Cancer: How to Reach Excellence?
}

\author{
Dr. Mehmet Illker Gökce, Dr. Yaşar Bedük \\ Ankara Üniversitesi Tıp Fakültesi, Üroloji Anabilim Dalı, Ankara, Türkiye
}

\section{Özet}

Transüretral mesane kanseri rezeksiyonu (TUR-Tm); primer ya da tekrarlayan kasa invaze olmayan mesane kanseri olgularının tanı, evreleme ve tedavisinde kullanılan temel cerrahi yöntemdir. Bu nedenle bu cerrahide mükemmelliğe ulaşılması oldukça önemlidir. Bu derlemede başarılı bir TUR-Tm yapılması için dikkat edilmesi gereken hususlar ve başarının arttıılması için kullanılabilecek teknolojik gelişmelerin özetlenmesi amaçlanmaktadır. Küçük tümörlerin rezeksiyonu en-blok, daha büyük tümörlerin rezeksiyonunda dış kısmından parça parça rezeksiyona başlanmalı, sonra taban kısmı rezeke edilmeli ve altta yatan kas tabakasından rezeksiyon yapılmalıdır. Bipolar sistemlerde elektrik akımı monopolar sistemlerin aksine hastanın vücudu üzerinden değil cihaz üzerinden devresini tamamlamaktadır. Bu nedenle obturator sinir refleksi riski de daha azdır. İki yöntem arasında etkinlik ve komplikasyon oranları açısından bir fark saptanmamıştır. Mesane kanserlerinin lazer ablasyonunun lokal anestezi altında uygulanabilmektedir. Obturator sinir refleksinin görülmediği ve kanamanın da nadiren görüldüğü bildirilmiştir. Beyaz ışık sistoskopi ile yüzeyden kabarık olmayan yüksek dereceli lezyonların ve papiller tümöral oluşumların lateral sınırlarının yeterince hassas bir şekilde belirlenemeyebileceği üzerinde durulmaktadır. Bu amaçla kullanılan yeni görüntüleme yöntemleri tedavi etkinliğini arttırmışıı. Bu yöntemler; Fotodinamik tanı (FDT), Dar bant görüntüleme (DBG), Konfokal lazer mikroendoskopi (KLM), Optikal koherans tomografi (OKT) olarak sıralanabilir. Mesane kanserinde TUR-Tm uygulaması mesane kanserinin tanı, evreleme ve tedavisinde en önemli adımdır. TUR-Tm'nin en iyi şekilde yapılması uygun evreye göre uygun adjuvan tedavinin seçilmesini ve hastalığın nüks ve progresyon oranlarının düşürülmesini sağlayacaktır. Bu amaçla mevcut uygulanan TUR-Tm tekniğinin geliştirilmesi ve iyi bir temel eğitim şarttır. Ayrıca etkinliğin arttırılması için hem kullanılan enerji kaynaklarının, hem de görüntüleme sistemlerinin geliştirilmesi ve yeni sistemlerin uygulamaya konulması gereklidir. (Üroonkoloji Bülteni 2014;13:88-92)

Anahtar Kelimeler: Mesane kanseri, transüretral rezeksiyon, bipolar TUR, Fotodinamik tanı, Optikal koherans tomografi

\begin{abstract}
Summary
Transurethral resection of bladder cancer (TUR-B) is the primary surgical method for the diagnosis, staging and treatment of primary or recurrent non-muscle-invasive bladder cancer. For this reason, reaching a level of excellence is of upmost importance. In this review, we aimed to summarize important points and technological developments to maintain successful TUR-B. Resection of smaller tumors should be made en bloc and for larger tuomors, resection should start from the outer portion and the base of the tumor should be resected thereafter together with the underlying muscle layer. In bipolar systems, the electrocautery circuit is completed through the resection loop in contrast to that in monopolar systems. This maintains lower rates of obturator reflex. Both techniques are similar in terms of efficacy and complications. Laser ablation of bladder cancer can be made under local anesthesia. Obturator nerve reflex is not observed and bleeding is also rare. It has been suggested that white light cystoscopy is not precise enough to detect flat highgrade lesions and lateral borders of the tumors. For this reason, new imaging methods have been established. These methods can be listed as follows: photodynamic diagnosis, narrow band imaging, confocal laser endomicroscopy and optical coherence tomography. TUR-B is the most important step in diagnosis, staging and treatment of bladder cancer. Best practice of TUR-B will aid in deciding appropriate adjuvant treatment and for certain stages and decreasing recurrence and progression rates. For this reason, the importance of improving the techniques of TUR-B and the importance of adequate training programmes is obvious. Besides, to increase efficacy, devopment of energy sources and imaging modalities is mandatory. (Bulletin of Urooncology 2014;13:88-92)
\end{abstract}

Key Words: Bladder cancer, transurethral resection, bipolar TUR, photodynamic diagnosis, optical coherence tomography 


\section{Giriş}

Mesane kanseri üriner sistemin en sık görülen kanseri olup insidansı erkeklerde 9/100 000, kadınlarda ise 2/100 000'dir (1). Bu olguların da yaklaşık \%75'i kasa invaze olmayan mesane kanseri olgularıdır. Transüretral mesane kanseri rezeksiyonu (TUR$\mathrm{Tm})$, primer ya da tekrarlayan kasa invaze olmayan mesane kanseri olgularının tanı, evreleme ve tedavisinde kullanılan ana cerrahi yöntemdir. TUR-Tm hem tanı amaçlı hem de tedavi amaçlı uygulandığından komplikasyonların asgari ölçüde azaltıırken, tümör rezeksiyonunun azami ölçüde yapılması gereklidir. Bu cerrahinin başarısı hastanın ilerleyen dönemde nüks, progresyon ve buna bağlı sağkalım oranlarını belirgin etkilemektedir. Bu nedenle bu cerrahide mükemmelliğe ulaşılması oldukça önemlidir. Bu derlemede başarılı bir TUR-Tm yapılması için dikkat edilmesi gereken hususlar ve başarının arttırılması için kullanılabilecek teknolojik gelişmelerden bahsedilecektir.

\section{Transüretral Mesane Kanseri Rezeksiyonu (TUR-Tm) Önemi ve Amaçlar}

Kasa invaze olmayan mesane kanserlerinin transüretral rezeksiyonunda amaç görülebilen tüm tümöral oluşumların tamamen rezeke edilmesidir. Yapılan çalışmalarda TUR-Tm sonrasında ilk 3-6 ay içinde nüks görülmesinin tümörün nüks ve progresyonu için önemli bir risk faktörü olduğu gösterilmiştir $(2,3)$. Erken dönemde görülen bu nükslerin önemli bir kısmı da yapılan TUR-Tm'nin yetersizliğine bağlı görülmektedir.

Transüretral Mesane Kanseri Rezeksiyonu (TUR-Tm) Amaçlar 1. Tümörün histolojik tip, derece ve evresinin belirlenmesi için yeterli patolojik materyalin sağlanması

2. Tümörün varlığı, derinliği ve invazyon şeklinin belirlenmesi

3. Görülebilen tüm tümöral yapıların ve karsinoma in-situ (CiS) gibi direk görülemeyebilen tümöral yapıların tamamının rezeke edilmesi

4. Yukardaki amaçlara ulaşılırken, komplikasyonların mümkün mertebe azaltılması

Transüretral Mesane Kanseri Rezeksiyonu (TUR-Tm) Uygulamasında Başarının Arttırılması için Öneriler

TUR-Tm sırasında genel anestezi uygulaması, cerrahın işlem sırasındaki konforu açısından en uygun seçenektir. Ancak günümüzde rejyonel anestezi yöntemleri giderek artan sıklıkta uygulanmaktadır. Özellikle ileri yaştaki, yandaş solunum sistemi hastalığı olan kişilerde daha uygun bir seçenek olarak uygulanmaktadır. Rezeksiyona başlanmadan önce mutlaka bimanuel muayene yapılmalı ve tümörün fiske olup olmadığı ve yakın organlara invazyonu hakkında değerlendirme yapılmalıdır. Hasta litotomi pozisyonuna alındıktan sonra üretradan uygun ebattaki rezektoskop ile girilmelidir. Giriş sırasında üretrada herhangi bir tümöral oluşum olup olmadığı mutlaka değerlendirilmelidir. Mesaneye girildikten sonra tüm ürotelyum incelenmelidir. Üreter orifislerinin yerleşim yerleri görülmeli, patolojik bir oluşum varsa üreter orifisleri ile olan ilişkisi değerlendirilmelidir. Ayrıca mesane içinde süpheli alanlar varsa not edilmeli, divertikül varlığı ve içinde olabilecek tümöral oluşumlar değerlendirilmelidir. Anterior duvar ve mesane kubbesi mutlaka dikkatli bir şekilde gözlenmeli ve bunun için $70^{\circ}$ optik kullanılmalıdır.

Küçük tümörlerin rezeksiyonu en-blok yapılmalıdır. Tümörün tamamı ve altta yatan mesane duvarından bir bölüm tek bir adımda tamamen rezeke edilmelidir. Daha büyük tümörlerin rezeksiyonu tek bir adımda yapılamayacağından tümörün dış kısmından parça parça rezeksiyona başlanmalı, sonra taban kısmı rezeke edilmeli ve en son olarak da altta yatan kas tabakasından ve tümörün yan sınırlarındaki sağlam görülen alanlardan rezeksiyon yapılmalıdır (4). Rezeksiyon sırasında koagulasyondan mümkün mertebe kaçınılmalıdır. İşlem sonunda kanama odaklarına koagulasyon ile kanama kontrolü uygulanmalıdır.

Birden fazla tümör olması halinde, tümöral oluşumlar ayrı ayrı rezeke edilerek farklı kaplarda patolojiye gönderilmelidir. Tümör tabanına ait yapılan örnekleme de kas tabakasına olan invazyonun sağlıklı değerlendirilmesi için ayrı bir kap içinde patolojiye gönderilmelidir. Kasa invaze mesane kanseri ya da perivezikal yayılım şüphesi olan olgularda daha sonra radikal sistektomi uygulanabileceği düşünülerek, diversiyon tipi ve üretrektomi endikasyonunun belirlenmesi için prostatik üretradan biyopsi alınmalıdır. Biyopsiler saat 4 ve 8 hizasından mesane boynundan verumontanuma kadar uzanacak şekilde yapılmalıdır.

Büyük, solid ve invaziv karakterli tümörlerde, radikal sistektomi gerekli olabileceği düşünülerek, tümörün sınırlarında kas dokusu içerecek şekilde rezeksiyon yapılmalıdır. Tümörün merkezi kısmından rezeksiyon yapmaya çalışılması halinde elde edilecek doku sıklıkla nekrotik doku şeklinde rapor edilecektir ve gereksiz intraoperatif ve postoperatif kanamalara neden olacaktır.

Mesane kubbe ya da anterior duvarda bulunan tümörlerin rezeksiyonu da teknik olarak zorluk içermektedir. Özellikle prostatın büyük olduğu olgularda rezeksiyon daha da zorlaşmaktadır. Rezeksiyonun sağlıklı yapılabilmesi için mesanenin fazla doldurulmasından kaçınılmalıdır ve suprapubik bası uygulanarak tümörün yaklaştırılması ve düz bir zeminde rezeksiyonu sağlanmalıdır. İşlem sırasında hem irigasyon hem de tahliyeye izin veren rezektoskop sistemleri kullanılmalıdır ve rezeksiyon sırasında mesane yarı dolu olarak işlem yapılmalıdır. Bu sayede mesane perforasyonu ya da lateral duvarların inferior kısımlarından yapılan rezeksiyonlar sırasında gelişebilecek obturator sinir refleksi önlenebilir.

Retrograd rezeksiyon perforasyona neden olabileceği için genellikle uygulanmamaktadır. Ancak dar bir tabanı ya da ince bir sapı olan üst kısmı geniş papiller tümörlerin rezeksiyonunda retrograd rezeksiyon ile tümörün sapından ayrılması uygulanabilir.

Üreter orifisini içine alan ya da orifisten kaynaklı tümörler de rezeksiyonu zor olan başka bir noktadır. Eğer tümörün tamamen rezeksiyonu için üreter orifislerinin rezeksiyonu gerekiyorsa bundan kaçınılmamalıdır. Ancak rezeksiyon sonrasında koagulasyon yapılmamalıdır. Orifislerin görülebildiği durumlarda üreterlerin rezeksiyon öncesi kateterizasyonu da uygulanabilir.

Rezeksiyon kalitesinin arttırılması öncelikle iyi bir görüntü ile mümkündür. Bunun sağlanması için gereksiz kanamalardan kaçınılmalıdır. Özellikle çoklu tümörlerin rezeksiyonu sırasında bir tümörün rezeksiyon işlemi bitirildiğinde diğer tümöre geçilmeden önce ilk tümörün tabanına ait kanama kontrolü tamamlanmalıdır. Ayrıca büyük solid tümörlere eşlik eden küçük $(<5 \mathrm{~mm})$ invaziv karakterde olmayan tümörlerin rezeke edilmek yerine koagulasyon ile fulgure edilmesi hem kanamanın daha az olmasını sağlayacak hem de perforasyona bağlı işlemin yarıda kesilmesi gibi riskleri en aza indirecektir. 
Divertikül içine yerleşen tümörlerin rezeksiyonu oldukça zor ve tecrübe isteyen bir durumdur. Divertikül duvarında kas tabakasının genellikle olmadığı göz önünde bulundurulmalıdır. Ayırca divertikül ağızları genellikle dardır. Öncelikle divertikül ağzının rezeksiyonu tümörün tam olarak görüntülenebilmesini sağlar. Özellikle tümörün küçük olduğu ve invaziv karakterli olmadığı durumlarda yüzeyel rezeksiyon ya da fulgurasyon uygulanabilir.

Mesane içindeki tümörün tam rezeksiyonu yalnızca dışarıdan görünen kısmın rezeksiyonu ile mümkün olmamaktadır. Tümörüm mesane duvarına doğru invazyon gösteren kısmının da mutlak rezeksiyonu gereklidir. Ancak invazyon şeklinin tümörün görünen kısmına bakılarak tam olarak anlaşılması mümkün değildir. Mesane lümenine doğru büyük bir uzanım gösteren tümör mesane duvarında önemli bir invazyon göstermeyebileceği gibi, mesane lümeninde küçük papiller bir görüntüsü olan tümörün mesane duvarı içinde yaygın ve derin invazyonu bulunabilir. Yapılan bir çalışmada rezeksiyonun tümör tabanında derinleştirildiği ve görülen tümörün $2 \mathrm{~cm}$ lateralini de içerecek şekilde rezeksiyon yapıldığında \%35 rezidüel tümör saptanmıştır (5).

\section{Transüretral Mesane Kanseri Rezeksiyonu (TUR-Tm) Teknik} Gelişmeler

Klasik TUR-Tm uygulamalarında monopolar koter sistemi kullanılmaktadır. Bu sistem kullanıldığında iki önemli komplikasyon; TUR sendromu ve obturator sinir refleksidir. Özelikle obturator sinir refleksine bağlı mesane perforasyonu gelişmesi halinde tam rezeksiyon yapılamayacaktır. Bu nedenle günümüzde TUR-Tm uygulamasında bipolar koter sistemli rezektoskoplar ve lazer ablasyon teknikleri giderek artan sıklıkta kullanılmaktadır.

Bipolar Sistem ile Transüretral Mesane Kanseri Rezeksiyonu (TUR-Tm) Uygulaması

Bipolar TUR özellikle iyi huylu prostat büyümesinin cerrahi tedavisinde yaygın olarak kullanılmaktadır. Hastaların orta ve uzun dönem takiplerinde klasik TUR ile karşılaştırıldığında benzer etkinlik ve azalmış komplikasyon oranları sağladığını gösteren çalışmalar vardır (6). Bipolar TUR'da izotonik solüsyon kullanılmaktadır ve TUR sendromu riski minimaldir. Ayrıca elektrik akımı monopolar sistemlerin aksine hastanın vücudu üzerinden değil cihaz üzerinden devresini tamamlamaktadır. Bu nedenle obturator sinir refleksi riski de daha azdır. Rose ve ark. tarafından yapılan çalışmada bipolar ve monopolar sistemler 56 hastada karşılaştırılmış ve etkinlik ve komplikasyon oranları açısından bir fark saptanmamıştır (7). Ancak monopolar TUR yapılan grupta 24 hastanın ikisinde obturator sinir refleksi izlenirken bipolar TUR grubunda 32 hastanın hiçbirinde izlenmemiştir.

Başka bir çalışmada bipolar TUR-Tm yapılan 121 hastanın sonuçları retrospektif olarak değerlendirilmiştir. Toplamda 16 $(\% 13,2)$ hastada komplikasyon izlenmiştir. Üç hastada $(\% 2,5)$ transfüzyon gerektiren kanama, iki hastada $(\% 1,7)$ mesane perforasyonu, altı hastada $(\% 4,9)$ obturator sinir refleksi ve beş hastada $(\% 4,1)$ üretral darlık izlenmiştir. TUR sendromu ise hiçbir hastada izlenmemiştir (8). Karşılaştırılması gereken önemli noktalardan biri de bipolar TUR-Tm uygulamalarında elde edilen patolojik örneklerin kalitesidir. Bu konu üzerine litertürde tek çalışma bulunmaktadır ve monopolar ve bipolar TUR-Tm yapılan 22 hastanın (her 2 grupta $11^{\prime}$ er hasta) patolojik örnek kaliteleri karşılaştırılmıştır ve arada anlamlı bir fark saptanmamıştır (9).

Mevcut veriler ışığında bipolar TUR-Tm, her ne kadar prospektif randomize karşılaştırma yapan geniş kapsamlı bir çalışma bulunmasa da mesane kanseri tedavisinde güvenle kullanılabilecek bir yöntem olarak görülmektedir.

\section{Mesane Tümörlerinin Transüretral Lazer Ablasyonu}

Değişiközelliktekilazerlerürolojikcerrahide değişikendikasyonlarla yaygın olarak kullanılmaktadır. Mesane kanseri tedavisinde yaygın olarak kullanılan lazer türleri, neodymium:yttrium-aluminium garnet (Nd:YAG), potassium-titanyl-phosphate (KTP:YAG) ve holmium:YAG (Ho:YAG) lazerlerdir. Mesane kanserlerinin lazer ablasyonunun lokal anestezi altında uygulanabileceği ve obturator sinir refleksinin görülmediği ve kanamanın da nadiren görüldüğü bildirilmiştir $(10,11)$. Lazer ablasyonun en önemli dezavantajı patolojik örnek alınmasında sıkıntı olmasıdır. Ancak holmium lazer ile en-blok enükleasyon tekniği tarif edilmiştir. Yapılan bir çalışmada evre Ta-T1 olan 152 hastada teknik olarak uygulanabildiği ve hastaların tamamında patolojik inceleme için uygun doku elde edilebildiği belirlenmiştir (11). Ancak yine de lazer uygulamalarının günümüz koşullarında mesane kanserinin endoskopik tedavisi için standart tedavi olma şansı bulunmamaktadır. Yalnızca lokal anestezi uygulaması zorunlu olan, daha önceden düşük dereceli olan ve submukozal invazyonu olmadığı gösterilmiş ve sitoloji sonucu negatif olgularda uygulanabilir bir tedavi yöntemidir.

\section{Mesane Tümörü Rezeksiyonunda Yeni Optik Görüntüleme Metodları}

Mesane kanserinin transüretral rezeksiyonunda en önemli nokta daha önce de belirtildiği gibi mevcut tümöral oluşumların tamamının rezeke edilmesidir. Bu amaca ulaşılabilmesi için de tümöral oluşumların net olarak görüntülenebilmesi, özellikle iyi huylu inflamatuvar değişikliklerin karsinoma in-situ'dan ayırt edilebilmesi gereklidir. Günümüzde standart olarak kullanılan beyaz ışık sistoskopi sisteminin bu amaca ulaşmakta yeterli olmayabileceği yönünde görüşler mevcuttur (12). Özellikle yüzeyden kabarık olmayan yüksek dereceli lezyonların ve papiller tümöral oluşumların lateral sınırlarının yeterince hassas bir şekilde belirlenemeyebileceği üzerinde durulmaktadır. Bu özellikler karsinoma in-situ gibi kötü prognostik faktörlerin tanı alamamasına ya da mevcut tümörlerin tam olmayan rezeksiyonuna ve buna bağlı nüks ve progresyona neden olabilmektedir. Re-TUR yapılan olgularda saptanan yüksek nüks oranlarının da beyaz ışık sistoskopi sisteminin yetersizliğinden kaynaklandığı yönünde görüşler mevcuttur.

Bu amaçla kullanılan yeni görüntüleme yöntemleri şunlardır;

1. Fotodinamik tanı (FDT)

2. Dar bant görüntüleme (DBG)

3. Konfokal lazer mikroendoskopi (KLM)

4. Optikal koherans tomografi (OKT)

\section{Fotodinamik Tanı (FDT)}

FDT yönteminde fotosensitif protoporfirin analogları kullanılmaktadır. İntravezikal olarak verildikten sonra 375-440 $\mathrm{nm}$ dalga boyu aralığında mavi ışık ile inceleme yapılır. BeşALA ya da HAL kanser hücrelerinde selektif olarak birikir ve mavi ışık altında kırmızı görüntü elde edilir. Elde edilen görüntü makroskopik olarak seçici bir görüntü sağlar. Elde edilen görüntü 
alanı beyaz ışık sistoskopisine benzer olup yalnızca tümöral doku kırmızı renk şeklinde görülür. PDT uygulamalarında daha önceki BCG uygulamalarına bağlı veya cerrahın öğrenme eğrisine bağlı olarak \%30'a varan oranlarda yanlış pozitif sonuçlar elde edilebilmektedir $(13,14)$. İşlem sırasındaki kanamalara bağlı görüntüdeki bozulmalar ve işlem öncesi kateterizasyon ihtiyacı kullanımı sınırlayan faktörlerdir.

Yapılan çalışmalarda PDT ile yapılan biyopsi ya da rezeksiyonlar ile (özellikle karsinoma in-situ için) duyarlıığın arttığı gösterilmiş̧tir $(15,16)$. Çalış̧maların sonuçlarının sistemik metaanalizinde PDT ile beyaz ışık sistoskopiye göre daha iyi duyarlılık sonuçları elde edilmiştir (\%92 vs \%71) ancak, PDT'nin özgüllük sonuçları beyaz ışık sistoskopiye göre daha düşüktür (\%63 vs \%81) (16). PDT ile yapılan TUR-Tm sonrası rekürrens ve progresyon oranları üzerine yapılan çalışmalardan çelişkili sonuçlar elde edilmiştir $(16,17,18)$. Yapılan çalışmalarda her ne kadar rekürrens oranlarında azalma ve rekürrense kadar geçen süre de anlamlı uzama tespit edilmiş olsa da $(19,20)$, TUR-Tm sonrasında intravezikal kemoterapi alan olgularda rekürrens oranlarına olan etkisini değerlendiren prospektif randomize bir çalışma bulunmamaktadır.

\section{Dar Bant Görüntüleme (DBG)}

Dar bant görüntüleme tekniğinde mesane kanserli doku ile normal ürotelyum arasındaki doku kontrast farkı ortaya çıkarılır. Bunun için beyaz ışı̆ı iki ayrı dalga boyunda (415 ve $540 \mathrm{~nm}$ ) gönderebilen bir ışı kaynağı kullanılır ve belli dalga boyundaki ışı̆ın hemoglobin tarafından emilmesi ile kapiller damarlar ile normal mukozanın ayırt edilmesi sağlanır. Mesane tümörü olan alanların normal mukozaya göre daha fazla damarlanma içerdiği için farklı görülmesi sağlanacaktır. Bu sayede özellikle yüzeyden kabarık olmayan karsinoma in-situ gibi beyaz ışık sistoskopide atlanabilecek alanların tanınmasında kolaylık sağlanacaktır. Ayrıca tümörün lateral sınrılarında rezeksiyon sınırları da daha sağlıklı belirlenebilecektir. Bununla birlikte dar bant görüntüleme ile \%36'ya varan oranlarda yanlış pozitiflik sonuçları da bildirilmiştir $(21,22)$. Özellikle adjuvan BCG tedavisi alanlarda inflamasyonun etkisi ile damarlanma artışı saptandığı için yanlış pozitif sonuçlar ortaya çıkabileceği düşünülmektedir. Rezeksiyon sırasında ortaya çıkabilecek kanamalar da mesanenin görüntülenmesinde sorunlara neden olabilmektedir.

Dar bant görüntüleme ile retrospektif çalışmalarda \%93-\%100'e varan oranlarda duyarlıık, \%65-\%82 oranında özgüllük sonuçları elde edilmiştir $(22,23,24)$. Karsinoma in-situ olguları için de $\% 90$ duyarlıık ve \%75 özgüllük sonuçları bildirilmiştir (22).

\section{Konfokal Lazer Mikroendoskopi (KLM)}

$\mathrm{Bu}$ görüntüleme yönteminde konfokal mikroskopi ile fiberoptik teknolojisi kombine edilmektedir. KLM günümüzde gastrointestinal sistem ve solunum sisteminin endoskopik görüntülemesinde kullanılmaktadır (25). KLM ile dokuda şüphelenilen alanların mikroskopik yapısı ve hücresel morfolojisi görüntülenmiş olur (26). KLM uygulaması için 2-6 mm'lik görüntüleme probu standart sistoskop ya da rezektoskopun çalışma kanalından gönderilir. Probun görüntü sağlaması için doku ile direk teması gerekmektedir. Tüm mesanenin prob yardımı ile incelenmesi mümkün olmayacağından, önce normal sistoskopi yapılıp şüpheli görünen alanların KLM ile ayrıca incelenmesi önerilmektedir.
Probun doku ile direk teması gerektiğinden mesane anterior duvar, kubbe ya da mesane boynu yüksek olgularda mesane çıkımına yakın alanların görüntülenmesinde problemler oluşabilmektedir. Bu nedenle 1,4 mm çapında daha ince bir probun bükülebilir bir sistoskop içinden gönderilerek işlem yapılması da önerilmektedir (27).

\section{Optikal Koherans Tomografi (OKT)}

OKT teknik olarak elastik ışık huzmeleri saçan ve bu huzmelerin doku tarafından emilmesi ile görüntü sağlayan bir cihazdır. Temel özelik olarak ultrasonografiye benzer ancak ultrasonda gönderilen ses dalgalarının dokudan yansıması ile görüntü elde edilirken OKT'de ışık huzmelerinin emilim özelliklerine göre görüntü elde edilir. OKT'nin özelliği kesitsel görüntüleme ile gerçek zamanlı mesane kanseri evrelemesi sağlamasıdır (28). Doku tarafından emilen ışık huzmelerinin derecesine göre doku derinliği tahmin edilir ve mesane duvarındaki 3 ana tabaka görüntülenmiş olur. Mesane kanseri tarafından dokudaki invazyon ile bu üç tabakanın ayrımı bozulur ve böylece tümörün dokudaki derinliği irdelenmiş olur. KLM'ye benzer şekilde OKT kullanımı için de sistoskop çalışma kanalından gönderilen bir prob yardımı ile görüntüleme yapilır. Tüm mesanenin bu şekilde incelenmesi mümkün olmadığından şüpheli görülen alanların ayrıca değerlendirilmesi önerilmektedir.

Bahsedilen görüntüleme yöntemleri beyaz ışı sistoskopiye göre daha yüksek duyarlıık sonuçları elde edilmesini sağlasa da eşlik eden pek çok dezavantajı da birlikte getirmektedir. Öncelikle yüksek yanlış pozitif sonuç oranları önemli bir problemdir. Ayrıca bu işlemlerin uygulaması ve elde edilen görüntünün yorumlanması için belli bir tecrübe ve öğrenme eğrisinin tamamlanması gerekmektedir. Sistemin öncelikli kurulumu ayrıcı PDT için gerekli olan protoporfirin analoglarının getireceği maliyet de göz önünde bulundurulmalıdır. Yanlış pozitiflik oranlarının düşürülmesi için bazı yöntemlerin birlikte kullanılması da önerilmektedir. Ancak bu durum hem 2 yöntemin maliyetini hem de iki yöntemi birlikte uygulayabilecek tecrübedeki hekim gerekliliğini ortaya çıkaracaktır.

\section{Sonuç}

Mesane kanserinde TUR-Tm uygulaması mesane kanserinin tanı, evreleme ve tedavisinde en önemli adımdır. TUR-Tm'nin en iyi şekilde yapılması uygun evreye göre uygun adjuvan tedavinin seçilmesini ve hastalığın nüks ve progresyon oranlarının düşürülmesini sağlayacaktır. Bu amaçla mevcut uygulanan TURTm tekniğinin geliştirilmesi ve iyi bir temel eğitim şarttır. Ayrıca etkinliğin arttırıması için hem kullanılan enerji kaynaklarının hem de görüntüleme sistemlerinin geliştirilmesi yeni sistemlerin uygulamaya konulması gereklidir.

\section{Kaynaklar}

1. Ferlay J, Bray F, Forman D, et al. GLOBOCAN 2008 v1.2, Cancer Incidence and Mortality Worldwide: IARC CancerBase No. 10 2010, International Agency for Research on Cancer: Lyon, France.

2. Lee $\mathrm{SE}$, Jeong IG, Ku H, et al. Impact of transurethral resection of bladder tumor: analysis of cystectomy specimens to evaluate for residual tumor. Urology 2004;63:873-877.

3. Holmang S, Johansson SL. Stage TA-T1 bladder cancer: the relationship between findings at first followup cystoscopy and subsequent recurrence and progression. J Urol 2002;167:1634-1637. 
Gökce ve ark.

Kasa Invaze Olmayan Mesane Kanserinde Transüretral Mesane Kanseri Rezeksiyonu (TUR-Tm): Nasıl Mükemmelliğe Ulaşılabilinir?

4. Richterstetter M, Wullich B, Amann $\mathrm{K}$, et al. The value of extended transurethral resection of bladder tumour (TURBT) in the treatment of bladder cancer. BJU Int 2012;110:E76-79.

5. Kolozsy Z. Histopathological 'self-control' in TUR of bladder tumors. Br J Urol 1991;67:162-164.

6. Mamoulakis C, Trompetter M, de la Rosette J. Bipolar transurethral resection of the prostate: the 'golden standard' reclaims its leading position. Curr Opin Urol 2009;19:26-32.

7. Rose A, Suttor S, Goebell PJ, et al. Transurethral resection of bladder tumors and prostate enlargement in physiological saline solution (TURIS). A prospective study. Urologe A 2007;46:1148-1150.

8. $\mathrm{Pu} X Y$, Wang $H P, W u ~ Y L$, Wang $X H$. Use of bipolar energy for transurethral resection of superficial bladder tumors: long-term results. J Endourol 2008;22:545-549.

9. Wang DS, Bird VG, Leonard VY, et al. Use of bipolar energy for transurethral resection of bladder tumors: pathologic considerations. J Endourol 2004;18:578-582.

10. Soler-Martinez J, Vozmediano-Chicharro R, Morales-Jimenez $P$, et al. Holmium laser treatment for low grade, low stage, noninvasive bladder cancer with local anesthesia and early instillation of mitomycin C. J Urol 2007; 178:2337-2339.

11. Zhu $Y$, Jiang $X$, Zhang J, et al. Safety and efficacy of holmium laser resection for primary nonmuscle-invasive bladder cancer versus transurethral electroresection: single-center experience. Urology 2008;72:608-612.

12. Grossman $H B$, Soloway $M$, Messing $E$, et al. Surveillance for recurrent bladder cancer using a point-of-care proteomic assay. JAMA 2006;295:299-300.

13. Koenig F, McGovern FJ, Larne R, et al. Diagnosis of bladder carcinoma using protoporphyrin IX fluorescence induced by 5 -aminolaevulinic acid. BJU Int 1999;83:129-135.

14. Ray ER, Chatterton K, Khan MS, et al. Hexylaminolaevulinate fluorescence cystoscopy in patients previously treated with intravesical bacille Calmette-Guerin. BJU Int 2010;105:789-794.

15. Kausch I, Sommerauer M, Montorsi F, et al. Photodynamic diagnosis in non-muscle-invasive bladder cancer: a systematic review and cumulative analysis of prospective studies. Eur Urol 2010;57:595-606.

16. Mowatt G, N'Dow J, Vale L, et al. Aberdeen Technology Assessment Review (TAR) Group. Photodynamic diagnosis of bladder cancer compared with white light cystoscopy: Systematic review and metaanalysis. Int J Technol Assess Health Care 2011;27:3-10.
17. Schumacher MC, Holmang S, Davidsson T, et al. Transurethral resection of non-muscle-invasive bladder transitional cell cancers with or without 5-aminolevulinic acid under visible and fluorescent light: results of a prospective, randomised, multicentre study. Eur Urol 2010;57:293-299.

18. Stenzl A, Penkoff H, Dajc-Sommerer E, et al. Detection and clinical outcome of urinary bladder cancer with 5-aminolevulinic acidinduced fluorescence cystoscopy: a multicenter, randomized, double-blind, placebo-controlled trial. Cancer 2011;117:938-947.

19. Stenzl A, Burger M, Fradet $Y$, et al. Hexaminolevulinate guided fluorescence cystoscopy reduces recurrence in patients with nonmuscle invasive bladder cancer. J Urol 2010;184:1907-1913.

20. Grossman HB, Stenzl A, Fradet Y, et al. Long-term decrease in bladder cancer recurrence with hexaminolevulinate enabled fluorescence cystoscopy. J Urol 2012;188:58-62.

21. Herr HW, Donat SM. Reduced bladder tumour recurrence rate associated with narrow-band imaging surveillance cystoscopy. BJU Int 2011;107:396-398.

22. Tatsugami K, Kuroiwa K, Kamoto T, et al. Evaluation of narrow-band imaging as a complementary method for the detection of bladder cancer. J Endourol 2010;24:1807-1811.

23. Cauberg EC, Kloen S, Visser $M$, et al. Narrow band imaging cystoscopy improves the detection of non-muscle-invasive bladder cancer. Urology 2010;76:658-663.

24. Herr HW, Donat SM. A comparison of whitelight cystoscopy and narrow-band imaging cystoscopy to detect bladder tumour recurrences. BJU Int 2008;102:1111-1114.

25. Wallace MB, Meining A, Canto MI, et al. The safety of intravenous fluorescein for confocal laser endomicroscopy in the gastrointestinal tract. Aliment Pharmacol Ther 2010;31:548-552.

26. Sonn GA, Jones SN, Tarin TV, et al. Optical biopsy of human bladder neoplasia with in vivo confocal laser endomicroscopy. J Urol 2009;182:1299-1305.

27. Adams W, Wu K, Liu JJ, et al. Comparison of 2.6- and 1.4-mm imaging probes for confocal laser endomicroscopy of the urinary tract. J Endourol 2011;25:917-921.

28. Goh AC, Tresser NJ, Shen SS, Lerner SP. Optical coherence tomography as an adjunct to white light cystoscopy for intravesical real-time imaging and staging of bladder cancer. Urology 2008;72:133-137. 